\title{
Study of clinical risk factors and predictors of post stroke vascular cognitive impairment
}

\author{
Sejwar A. ${ }^{1}$, Gopal Krishna ${ }^{2}$, A. Dhiran ${ }^{3}$, Dubey T. N. ${ }^{4}$ \\ ${ }^{1}$ Dr. Anil Sejwar, Assistant Professor, ${ }^{2}$ Dr. Gopal Krishna, Senior Resident, both authors are affiliated with department of \\ Medicine, Gandhi Medical Collage, Bhopal. ${ }^{3}$ Dr. Arpit Dhiran, Consultant, Red Cross Hospital Bhopal and Ex-Resident \\ GMC, Bhopal, ${ }^{4}$ Dr. T. N. Dubey, Professor (Neurologist), Department of Medicine, GMC, Bhopal, MP, India.
}

Corresponding Author: Dr. Gopal Krishna, Senior Resident, Department of Medicine, Gandhi Medical College and Associated Hospitals Bhopal. Email: g.krishnaahirwar@gmail.com

\begin{abstract}
Introduction: Cognitiveimpairment due to cerebrovascular disease is termed" vascular cognitive Impairment "(VCI) and forms a spectrum that includes vascular dementia and milder forms of cognitive impairment. Vascular cognitive impairment has some varied and diverse aetiology. This is particularly important as apart from age vascular risk factors, are the most important and presently the only treatable precursor to dementia. This prospective observational study was carried out in indept. ofmedicine, GMC Bhopal. Methods: A standard protocol was applied at admission and 3 months after stroke, this protocol included clinical, functional and cognitive assessments,various lab tests and MMSE. Results: Amongst the various risk factors hypertension, diabetes mellitus, prior stroke, dyslipidemia, ischemic heart disease, tobacco chewing, smoking, family history of dementia was more frequently seen in vascular cognitive impairment group. In this study, the frequency of patients having post stroke vascular cognitive impairment (VCI) is $54 \% .18 \%$ of the patients had $\mathrm{VaD}$ (Vascular dementia), 36\% of the patients had VMCI (vascular mild cognitive impairment), $46 \%$ of the patients had NO VCI (no vascular cognitive impairment. There was significant association of risk factors like Hypertension $(\mathrm{p}=0.022)$ diabetes mellitus $(\mathrm{P}=0.038)$, dyslipidaemia $(\mathrm{p}=0.034)$, prior stroke $(\mathrm{p}=0.046)$ with development of vascular cognitive impairment. Post stroke dementia has considerable morbidity. Conclusion: The predictors of development of Vascular cognitive impairment following stroke in this study are lower educational status, Hypertension, Diabetes mellitus, Dyslipidemia, Prior stroke,urinary incontinence,High sys. BP, NIHSS score, LDL level, abnormal ECG, Strategic site lesion and greater severity of age related white matterchanges.
\end{abstract}

Key words- Cognitive impairment, Sejwar et al, Clinical predictors

\section{Introduction}

Cognitiveimpairment due to cerebrovascular disease is termed vascular cognitive Impairment (VCI) and forms a spectrum that includes vascular dementia and milder forms of cognitive impairment referred to as vascular mild cognitive impairment [1]. While $\mathrm{VaD}$ is the second most common, the milder form VMCI is much more common. Nearly half of individuals with VMCI convert todementiaafter five years [2].

Vascular cognitive disorders are poised to become the silent epidemic of the $21^{\text {st }}$ century and contribute significantly to mortality, disability, and decreased quality of life [3]. It is now clear that VCI is not a single

Manuscript received: $10^{\text {th }}$ February 2018

Reviewed: $20^{\text {th }}$ February 2018

Author Corrected: $28^{\text {th }}$ February 2018

Accepted for Publication: $6^{\text {th }}$ March 2018 entity but represents a complex neurological disorder that occurs as a result of interaction between vascular risk factors such as hypertension, diabetes, obesity, dyslipidemia, and brain parenchymal changes such as macro and micro infarction, haemorrhages, white matter changes and brain atrophy occurring in aging brain. Since (VCI) is amenable to prevention and treatment, there is pressing need to identify factors that protect or predispose to it [4].

Vascular cognitive impairment (VCI) has some varied and diverse aetiology, the various forms include cognitive impairment following single strategic infarction, sub cortical (VCI), and multiinfarcts dementia, VCI rather than vascular dementia (VAD) is the more appropriate term, as the correct objective should be to identify the condition before it develops 


\section{Original Research Article}

into frank dementia. This is particularly important as apart from age, vascular risk factors, are the most important and presently the only treatable precursor to dementia. Post stroke dementia has been an emerging field of research over the last decade[5-10].

The frequency of post stroke dementia has been found to be higher than expected, stroke increases the risk of dementia [4-10] multiple times [8-10]. reason for a stroke patient to become demented are still insufficiently understood. All individuals with stroke do not develop dementia, therefore, it is important to determine the risk factors.

Some studies have investigated the risk factors, but there has not been a consensus about them $[6,7,8,10]$. Demographic, clinical, stroke related and lesion related radiological factors have been reported to predict dementia in stroke patients.

\section{Methodology}

Study type and place of study- This prospective observational study was carried out in department of medicine, Gandhi medical College and associated Hamidia Hospital Bhopal. This study covered population of Bhopal and neighbouring districts.

Methods and sample collection-A standard protocol was applied at admission and 3 months after stroke, this protocol included clinical, functional and cognitive assessments, hemogram and serum biochemistry, ECG, non contrast CT scan, 2d echo, carotid Doppler and MMSE(mini mental state examination). Association international pour recherche etc l'enseignement ensure neurologie (NiNDS-AIREN) criteria was used for vascular dementia.

Demographic and clinical characteristics included are age sex educational level (low level of education defined as Defined as less than 10 years of formal education), socioeconomic status, occupation, family history of dementia, smoking habits, hypertension, diabetes mellitus, hyper cholesterolemia, atrial fibrillation, ischemic heart disease, history of alcohol intake, transient ischemic attacks, prior stroke and any other ischemic illness.

All patients were subjected to cardiac examination included an electro cardiogram (ECG) and echo cardiography of the heart. Clinical features like urinary incontinence, sensory abnormality, gaitabnormality, bulbar features, peripheral signs of atherosclerosis and blood pressure were noted. Stroke severity was assessed by the national institute of health stroke scale (NIHSS).

Laboratory measurements included are blood sugar on admission, renal and liver functions and lipogram (serum total cholesterol (TC), triglycerides (TG), low density lipoprotein cholesterol LDL-c, high density lipoprotein cholesterol HDL-c complete blood picture.

Inclusion criteria-Patients were consecutive acute stroke patients either ischemic or haemorrhagic admitted over a period of 1 year in Hamidia hospital.

Exclusion criteria- Patients with aphasia, reduced level of consciousness, stroke associated with tumours, trauma, subarachnoid haemorrhage, patients with transient ischemic attack, with severe hearing and visual impairment, previously diagnosed case ofdementia/ cognitive impairment, mental retardation, history of psychosis or other psychiatric and neurological disorders, brain ischemia due to cardio respiratory arrest, anyneurological operation, patients not willing to participate were excluded.

Statisticalmethod- Chi square test was applied for analysis. mean standard deviation and $\mathrm{p}$ - value was calculated for various factors indifferent groups.

Cognitive assessment- Higher mental functions were clinically evaluated, for which Mini-Mental State Examination (MMSE) [11-12], a widely used scale for the screening test for dementia is used.

It consists of variety of questions grouped into seven categories, each representing a different cognitive domain or function (orientation to time, orientation to place, recitation of words, attention, calculation, recall of words, language, visual construction).

Memory assessment is done by asking questions (immediate -same as attention, recent-same as recall, remote-previous life events).

To determine whether patient had pre-stroke cognitive decline, a reliable proxy accompanying the patient was interviewed, retrospectively, as to whether patient exhibited any sign of cognitive impairment in the form of memory impairment, paraxial, aphasia, agnostics, executive dysfunction before stroke and interference with daily activities because of them.

Cognitive assessment is again done at follow up after 3 months to study cognitive impairment. 


\section{Results}

Table-1: Number of patients in different groups.

\begin{tabular}{|c|c|c|}
\hline Patient group & Frequency & Percent \\
\hline NOVCI & 46 & 46.0 \\
VMCI & 36 & 36.0 \\
VAD & 18 & 18.0 \\
Total & 100 & 100.0 \\
\hline
\end{tabular}

In this study, the frequency of patients having post stroke vascular cognitive impairment (VCI) is $54 \%$. $18 \%$ of the patients had Vat (Vascular dementia), 36\% of the patients had VMCI (vascular mild cognitive impairment), $46 \%$ of the patients had NO VCI (no vascular cognitive impairment).

There was no gender preponderance in both the group.

Table- 2: Mean age in different groups.

\begin{tabular}{|c|c|c|c|c|c|c|}
\hline \multirow{2}{*}{} & \multicolumn{4}{|c|}{ Ptgroup } \\
\cline { 2 - 7 } & \multicolumn{2}{|c|}{ NOVCI } & \multicolumn{2}{c|}{ VMCI } & \multicolumn{2}{c|}{ VAD } \\
\cline { 2 - 7 } & Mean & $\begin{array}{c}\text { Standard } \\
\text { Deviation }\end{array}$ & Mean & $\begin{array}{c}\text { Standard } \\
\text { Deviation }\end{array}$ & $\begin{array}{c}\text { Standard } \\
\text { Deviation }\end{array}$ \\
\hline Age & 62 & 5 & 63 & 6 & 65 & 6 \\
\hline
\end{tabular}

\begin{tabular}{|c|c|c|c|c|c|c|}
\hline & & & & & \multicolumn{2}{|c|}{ Significance } \\
\hline & \multicolumn{2}{|c|}{ NOVCI } & \multicolumn{2}{|c|}{ VCI(VMCI \& VAD) } & & \\
\hline & Mean & $\begin{array}{c}\text { Standard } \\
\text { Deviation }\end{array}$ & Mean & $\begin{array}{l}\text { Standard } \\
\text { Deviation }\end{array}$ & $\begin{array}{c}\mathrm{T} \\
\text { test }\end{array}$ & $\begin{array}{c}\mathrm{P} \\
\text { Value }\end{array}$ \\
\hline Age & 62 & 5 & 64 & 6 & 1.96 & 0.05 \\
\hline
\end{tabular}

In our study mean age of patients having no vascular cognitive impairment is $62 \pm 5$ years. Mean age of patients having mild vascular cognitive impairment is $63 \pm 6$ years and Mean age of patient having vascular dementia (VaD) is $65 \pm 6$ years.

Table- 3: Socioeconomic status and Educational status in different groups.

\begin{tabular}{|c|c|c|c|c|c|c|c|}
\hline \multirow{2}{*}{} & \multicolumn{2}{|c|}{ NOVCI } & \multicolumn{2}{c|}{ VMCI } & \multicolumn{2}{c|}{ Significance } \\
\cline { 3 - 7 } & Count & $\begin{array}{c}\text { Row } \\
\text { N\% }\end{array}$ & Count & $\begin{array}{c}\text { Row } \\
\text { N\% }\end{array}$ & $\begin{array}{c}\text { Chi } \\
\text { square }\end{array}$ & $\begin{array}{c}\text { P } \\
\text { Value }\end{array}$ \\
\hline \multirow{2}{*}{ Low education } & absent & 24 & $58.50 \%$ & 17 & $41.50 \%$ & 4.4 & 0.04 \\
\cline { 2 - 7 } & present & 22 & $37.30 \%$ & 37 & $62.70 \%$ & & \multirow{2}{*}{0.30} \\
\hline \multirow{2}{*}{$\begin{array}{c}\text { Socioeconomic } \\
\text { status }\end{array}$} & low & 26 & $41.90 \%$ & 36 & $58.10 \%$ & 1.08 & \\
\cline { 2 - 7 } & middle & 20 & $52.60 \%$ & 18 & $47.40 \%$ & & \\
\hline
\end{tabular}

In this study $62 \%$ of the patients belongs to low socioeconomic status and $38 \%$ of patients belong to middle socioeconomic status. In our study, patients with vascular cognitive impairment 9VCI) had significantly lower educational status ( $\mathrm{p}=0.036$ ), as compared to those who did not develop vascular cognitive impairment (VCI). 
Original Research Article

Table-4: Risk factor profile in different groups.

\begin{tabular}{|c|c|c|c|c|c|c|c|}
\hline & & \multicolumn{4}{|c|}{ vci } & \multicolumn{2}{|c|}{ Significance } \\
\hline & & \multicolumn{2}{|c|}{ NOVCI } & \multicolumn{2}{|c|}{ VCI } & & \\
\hline & & Count & $\begin{array}{l}\text { Row } \\
\text { N\% }\end{array}$ & Count & $\begin{array}{l}\text { Row } \\
\text { N\% }\end{array}$ & $\begin{array}{c}\text { Chi } \\
\text { square }\end{array}$ & $\begin{array}{c}P \\
\text { value }\end{array}$ \\
\hline \multirow[t]{2}{*}{ Hypertension } & absent & 18 & $64.30 \%$ & 10 & $35.70 \%$ & \multirow[t]{2}{*}{5.23} & \multirow[t]{2}{*}{0.02} \\
\hline & present & 28 & $38.90 \%$ & 44 & $61.10 \%$ & & \\
\hline \multirow[t]{2}{*}{ Diabetes mellitus } & absent & 30 & $55.60 \%$ & 24 & $44.40 \%$ & \multirow[t]{2}{*}{4.32} & \multirow[t]{2}{*}{0.04} \\
\hline & present & 13 & $34.80 \%$ & 30 & $65.20 \%$ & & \\
\hline \multirow[t]{2}{*}{ Alcohol } & absent & 36 & $43.40 \%$ & 47 & $56.60 \%$ & \multirow[t]{2}{*}{1.36} & \multirow[t]{2}{*}{0.24} \\
\hline & present & 10 & $58.80 \%$ & 7 & $41.20 \%$ & & \\
\hline \multirow[t]{2}{*}{ Smoking } & no & 31 & $43.70 \%$ & 40 & $56.30 \%$ & \multirow[t]{2}{*}{0.54} & \multirow[t]{2}{*}{0.46} \\
\hline & yes & 15 & $51.70 \%$ & 14 & $48.30 \%$ & & \\
\hline \multirow[t]{2}{*}{ Tobacco chewer } & no & 31 & $47.70 \%$ & 34 & $52.30 \%$ & \multirow[t]{2}{*}{0.21} & \multirow[t]{2}{*}{0.64} \\
\hline & yes & 15 & $42.90 \%$ & 20 & $57.10 \%$ & & \\
\hline \multirow[t]{2}{*}{ Ischemic heart disease } & absent & 42 & $48.30 \%$ & 45 & $51.70 \%$ & \multirow[t]{2}{*}{1.4} & \multirow[t]{2}{*}{0.24} \\
\hline & present & 4 & $30.80 \%$ & 9 & $69.20 \%$ & & \\
\hline \multirow[t]{2}{*}{ Dyslipidemia } & absent & 31 & $55.40 \%$ & 25 & $44.60 \%$ & \multirow[t]{2}{*}{4.48} & \multirow[t]{2}{*}{0.03} \\
\hline & present & 15 & $34.10 \%$ & 29 & $65.90 \%$ & & \\
\hline \multirow[t]{2}{*}{ Prior stroke } & no & 38 & $52.10 \%$ & 35 & $47.90 \%$ & \multirow[t]{2}{*}{3.99} & \multirow[t]{2}{*}{0.05} \\
\hline & yes & 8 & $29.60 \%$ & 19 & $70.40 \%$ & & \\
\hline \multirow[t]{2}{*}{ Family history of dementia } & no & 43 & $47.30 \%$ & 48 & $52.70 \%$ & \multirow[t]{2}{*}{0.64} & \multirow[t]{2}{*}{0.42} \\
\hline & yes & 3 & $33.30 \%$ & 6 & $66.70 \%$ & & \\
\hline
\end{tabular}

There was significant association of risk factors like Hypertension $(\mathrm{p}=0.022)$ diabetes mellitus $(\mathrm{P}=0.038)$, dyslipidemia $(\mathrm{p}=0.034)$, prior stroke $(\mathrm{p}=0.046)$ with development of vascular cognitive impairment.

In this study, through risk factors like ischemic heart disease, tobacco chewing, smoking and family historyof dementia were more frequently seen in VCI (vascular cognitive impairment) group than NO-VCI group the difference is not significant.

In this study, the clinical parameters which significantly associated with development of vascular cognitive impairment are urinary incontinence $(\mathrm{P}=0.01)$, systolic blood $(\mathrm{p}=0.049)$, and baseline stroke severity score $(\mathrm{p}=<0.001)$.

The clinical parameters like gait abnormality, peripheral signs of atheros clerosis and atrial fibrillation are more frequently found in VCI group but the difference was not statistically significant. 
Original Research Article

Table-5: Clinical parameters in different groups.

\begin{tabular}{|c|c|c|c|c|c|c|c|}
\hline & & \multicolumn{4}{|c|}{ VCI } & \multicolumn{2}{|c|}{ Significance } \\
\hline & & \multicolumn{2}{|c|}{ NOVCI } & \multicolumn{2}{|c|}{ VCI } & & \\
\hline & & Count & $\begin{array}{l}\text { Row } \\
\text { N\% }\end{array}$ & Count & $\begin{array}{l}\text { Row } \\
\text { N\% }\end{array}$ & $\begin{array}{c}\text { Chi } \\
\text { square }\end{array}$ & $\begin{array}{c}\mathbf{P} \\
\text { Value }\end{array}$ \\
\hline \multirow[t]{2}{*}{ Gait abnormality } & absent & 39 & $45.90 \%$ & 46 & $54.10 \%$ & \multirow[t]{2}{*}{0} & \multirow[t]{2}{*}{0.96} \\
\hline & present & 7 & $46.70 \%$ & 8 & $53.30 \%$ & & \\
\hline \multirow[t]{2}{*}{ Bulbar features } & absent & 40 & $44.40 \%$ & 50 & $55.60 \%$ & \multirow[t]{2}{*}{0.88} & \multirow[t]{2}{*}{0.35} \\
\hline & present & 6 & $60.00 \%$ & 4 & $40.00 \%$ & & \\
\hline \multirow{2}{*}{$\begin{array}{l}\text { Peripheral signs of } \\
\text { atherosclerosis }\end{array}$} & absent & 36 & $50.70 \%$ & 35 & $49.30 \%$ & \multirow[t]{2}{*}{2.18} & \multirow[t]{2}{*}{0.14} \\
\hline & present & 10 & $34.50 \%$ & 19 & $65.55 \%$ & & \\
\hline \multirow[t]{3}{*}{ Handedness } & left & 1 & $14.30 \%$ & 6 & $85.70 \%$ & \multirow[t]{3}{*}{3.05} & \multirow[t]{3}{*}{0.08} \\
\hline & right & 45 & $48.40 \%$ & 48 & $51.60 \%$ & & \\
\hline & yes & 15 & $51.70 \%$ & 14 & $48.30 \%$ & & \\
\hline \multirow[t]{2}{*}{ Atrial fibrillation } & absent & 33 & $47.80 \%$ & 36 & $52.20 \%$ & \multirow[t]{2}{*}{0.3} & \multirow[t]{2}{*}{0.59} \\
\hline & present & 13 & $41.80 \%$ & 18 & $58.10 \%$ & & \\
\hline \multirow[t]{2}{*}{ Urinaryincontinence } & absent & 43 & $51.80 \%$ & 40 & $48.20 \%$ & \multirow[t]{2}{*}{6.63} & \multirow[t]{2}{*}{0.01} \\
\hline & present & 3 & $17.60 \%$ & 14 & $82.40 \%$ & & \\
\hline \multirow[t]{2}{*}{ Sensory abnormality } & absent & 36 & $43.90 \%$ & 46 & $56.10 \%$ & \multirow[t]{2}{*}{0.81} & \multirow[t]{2}{*}{0.37} \\
\hline & present & 10 & $55.60 \%$ & 8 & 44.4 & & \\
\hline
\end{tabular}

Table- 6: Laboratory parameters in different groups.

\begin{tabular}{|c|c|c|c|c|c|c|}
\hline & \multicolumn{9}{|c|}{ Vci } & \multicolumn{2}{c|}{ Significance } \\
\cline { 2 - 7 } & \multicolumn{2}{|c|}{ NOVCI } & \multicolumn{2}{c|}{ Vci } & \multirow{2}{*}{ P value } \\
\cline { 2 - 7 } & mean & $\begin{array}{c}\text { Standard } \\
\text { deviation }\end{array}$ & mean & $\begin{array}{c}\text { Standard } \\
\text { deviation }\end{array}$ & T test & 0.8 \\
\hline Total chol. & 135 & 32 & 142 & 50 & 1.98 & 0.041 \\
\hline LDL & 156 & 45 & 173 & 52 & 1.29 & 0.20 \\
\hline HDL & 44 & 3 & 43 & 3 & 1.71 & 0.091 \\
\hline Triglyceride & 179 & 77 & 157 & 49 & 1.05 & 0.297 \\
\hline $\begin{array}{c}\text { Blood sugar } \\
\text { on admission }\end{array}$ & 141 & 45 & 151 & 48 & & \\
\hline
\end{tabular}

\begin{tabular}{|c|c|c|c|c|c|c|c|}
\hline & \multicolumn{4}{|c|}{ vci } & \multirow{2}{*}{\multicolumn{2}{|c|}{ Significance }} \\
\hline & & \multicolumn{2}{|c|}{ NOVCI } & \multicolumn{2}{|c|}{ VCI } & & \\
\hline & & count & N\% & count & N\% & Chi square & P value \\
\hline \multirow[t]{2}{*}{ ECG } & normal & 31 & $55.4 \%$ & 25 & $44.6 \%$ & \multirow[t]{2}{*}{4.486} & \multirow[t]{2}{*}{0.034} \\
\hline & abnormal & 15 & $34.1 \%$ & 29 & $65.9 \%$ & & \\
\hline \multirow[t]{2}{*}{ 2d Echo } & normal & 22 & $50.0 \%$ & 22 & $50.0 \%$ & \multirow[t]{2}{*}{0.51} & \multirow[t]{2}{*}{0.477} \\
\hline & normal & 24 & $42.9 \%$ & 32 & $57.1 \%$ & & \\
\hline
\end{tabular}

The laboratory parameters which is significantly associated with vascular cognitive impairment is high LDL level $(\mathrm{p}=0.041)$. 


\section{Original Research Article}

The parameters like high blood sugar on admission, high triglycerides level, high cholesterol level were frequently found in vascular cognitive impairment group, but are not statistically significant. The abnormal ECG ( $p=0.034)$ is significantly associated with vascular cognitive impairment.

In our study the neuro-imaging features like strategic site lesion $(\mathrm{p}=0.002)$ and higher ARWMC score $(\mathrm{p}=0.001)$ were significantly associated with VCI.

There is no significant association of type of stroke (ischemic vs hemorrhagic), dominant hemisphere involvement and number of lesions with vascular cognitive impairment in our study.

Out of various demographic parameters, clinical parameters, laboratory parameters, risk factor profile and neuro-imaging features, none of them was significantly differ in VMCI (vascular mild cognitive impairment and VaD (vascular dementia) group.

\section{Discussion}

Cognitive impairment is commonly seen after stroke. It significantly adds to post-stroke morbidity besides physical disabilities caused by stroke itself, ultimately resulting in poor functional outcome over a period of time. Vast research has been done on post-stoke cognitive dysfunction,most of the data being from the developed countries with relatively scarce data from developing countries like ours. In the present study, the frequency of $\mathrm{VaD}$ was $18 \%$ whereas that of VMCI was $36 \%$. Most of the studies done previously had focused on $\mathrm{VaD}$ [13-15] with little emphasis on VMCI (mild cognitive impairment) [16-17] which may be considered as a prodromal phase of vaD.

Most of the studies revealed similar rates of post stroke dementia, khedr et al. [13] reporting a rate of $21 \%$ in a study of 81 patients at 3 months and sachdev et al[17] reporting a rate of $21.3 \%$ in individuals aged 50-85 years at 3-6 months after the incident stroke. Still higher rates were reported by pohjasvaaraet al[9], 31.8\% and Barba et al. [19] 30\%. Few authors such as Rasquin et al [16] 7.7\% and Madureira et al. [20] 6\% however had reported considerably lesser rates of PSD. Allan et al[24] studied long term incidence of dementia in older stroke survivors and found that around $23.9 \%$ of them developed dementia over a mean follow-up period of 3.79 years.

The wide range of variations in rates of PSD in these studies might be the result of different criteria which are used for diagnosing $\mathrm{VaD}$ as the sensitivity defers with each criterion. Thus, definition which is being used for diagnosing vaD must be given due consideration while interpreting the rates of PSD.

In the present series, patients who developed VCI had lower educational status and belonged to low socioeconomic status as compared to patients who did not develop VCI. This emphasizes the fact that those with lower level of education are more vulnerable to develop cognitive impairment after stroke probably due to the fact that those with higher level of education have more cognitive reserve thus increasing the thres hold of clinically manifested cognitive dysfunction. Farmers, unskilled workers such as laborers, and housewives constituted more than relatively similar observed patients in VCI group and were older than those in NOVCI group, although this difference was not significant.

Many other studies revealed that post-stroke cognitive impairment commonly develops in patients with higher age. In this series, patients who developed $\mathrm{VCl}$ were more likely to have diabetes mellitus, hypertension. Hebert et al found that diabetes, hypertension in females, and presence of Apo lipoprotein E were found to associated with vascular dementia as compared to controls. Pohjasvaara et al. found that total cholesterol, associated with post stroke dementia, in another study, hypertension, atrial fibrillation, ischemic heart disease, and family history of dementia were significantly found to be associated with post stroke dementia.

They also found that patients with $\mathrm{VaD}$ more frequently had higher LDL and lower HDL levels, although the difference was not significant. The risk factors predispose the individuals to develop VCI by increasing the risk of stroke itself and recurrent strokes leads to cumulative cognitive dysfunction ultimately leading to $\mathrm{VaD}$. So the more the risk factors, the more is the risk of developing recurrent strokes and hence the chances of developing VCI. Hyperglycemia during the acute phase of stroke may be stress related or may be due to preexisting diabetes. It may exacerbate the cellular damage in metabolically challenged tissue i.e. penumbra. It does so by inducing lactic acidosis as a 


\section{Original Research Article}

result of anaerobic metabolism and by producing free radicals. Lipid per oxidation further adds to the cellular damage. Beside this, insulin resistance also contributes to the risk of stroke [22]. Elevated LDL level is a wellknown risk factor for atherosclerosis which also affects intracranial vasculature as a result of endothelial dysfunction thus increasing the propensity to recurrent clinical and subclinical ischemic events and predisposing the individuals to cognitive impairment.

On statistical analysis, the parameters which were significantly associated with VCI are low level of education $(<10$ years of formal education), hypertension, diabetes mellitus, dyslipidemia, prior stroke, urinaryincontinence, In addition, we compared VMCI with VaD. However, the difference between two groups in various parameters was not statistically significant. Very few studies have compared these two subtypes of post-stroke cognitive Impairment [17]. In India, although, an attempthas been done to describe the pattern of vascular dementia by Allan et al. [24]. very few studies have prospectively evaluated post-stroke cognitive impairment to determine its predictors. Sundar et al studied post-stroke cognitive impairment after 3 months of incident stroke and found that impairment on either MMSE or Frontal assessment battery (FAB) was seen in $31.7 \%$ patients. They also found that memory impairment was more frequently seen in multiple infarct stroke compared to single infarct.

This study had several limitations. First, we excluded a fair number of patients for various reasons. This could have led to underestimation of the prevalence of post stroke cognitive dysfunction. Secondly, follow-up duration in this study was limited to 3 months. studies have revealed that cognitive impairment may improve over a period of time, hence, longer follow-up with larger homogenous study population is required to study the evolution of post- stroke cognitive impairment.

\section{Conclusion}

To conclude, post-stroke cognitive impairment is commonly seen and is associated with considerable morbidity and poor functional outcome. Both ischemic and hemorrhagic stroke may result in cognitive impairment.

The predictors of development of Vascular cognitive impairment following stroke in this study are lower educational status, Hypertension, Diabetes mellitus, Dyslipidemia, Prior stroke, Urinary incontinence, High systolic blood pressure, NIHSS score, LDL level, abnormal ECG, Strategic site lesion and greater severity of age related white matter changes. Better insight into the risk factors for post stroke cognitive impairment may provide preventive and therapeutic opportunities for Vascular cognitive impairment.

Advantages ofthis study- The post stroke cognitive impairment occurs inmajority of stroke patients. in our study we found that hypertension, diabetes mellitus, dyslipidemia, abnormal ECG, prior stroke with diagnosed cognitive impairment, low educational and socioeconomic status,tobacco and alcohol abuse can help in prediction of post stroke cognitive impairment.

Contribution by authors- Dr Anil and Dr Gopal prepared the manuscript after doing various testsin stroke patients and data analysis. Dr Arpit and Dr Anil collected the data from patients and done statistical analysis and involved in patient care. Dr T N Dubey supervised the study and helped in interpreting neurological parameters.

\section{Funding: Nil, Conflict of interest: None. Permission of IRB: Yes}

\section{References}

1. Hachinski VC, Bowler JV. Vascular dementia: Diagnostic Criteria For Research Studies. Neurology 1993; 2159-60.

2. Ingles JL, Wentzel C, Fisk JD, Rockwood K. Neuro psychological predictors of incident dementia in patients with vascular cognitive impairment, without dementia. Stroke. 2002 Aug;33(8):1999-2002.

3. Román GC. Vascular dementia may be the most commonform of dementia in the elderly. J Neurol Sci. 2002 Nov 15;203-204:7-10.

4. Erkinjuntti T, Román G, Gauthier S, Feldman H, Rockwood K. Emerging therapies for vascular dementia and vascularcognitive impairment. Stroke. 2004 Apr;35 (4):1010-7. Epub 2004 Mar 4.

5. Censori B, Manara O, Agostinis C, Camerlingo M, Casto L, Galavotti B, Partziguian T, Servalli MC, Cesana B, Belloni G, Mamoli A. Dementia after first stroke. Stroke. 1996 Jul;27(7):1205-10.

6. Inzitari D, Di Carlo A,Pracuccig et el.Incidents and Determinants of Post Stroke Dementia as Defined by A Informant Interview Method In Hospital Based Stroke Registry..Stroke1998;29:2087-2093. 
Original Research Article

7. Loeb C, Gandolfo C, Croce R, Conti M. Dementia associated with lacunar infarction. Stroke. 1992 Sep;23 (9): 1225-9.

8. Pohjasvaara T, Erkinjuntti T, Vataja R, Kaste M. Dementia three months after stroke. Baseline frequency and effect of different definitions of dementia in the Helsinki Stroke Aging Memory Study (SAM) cohort. Stroke. 1997 Apr;28(4):785-92.

9. Pohjasvaara T, Erkinjuntti T, Ylikoski R, Hietanen M, Vataja R, Kaste M. Clinical determinants of poststroke dementia. Stroke. 1998 Jan; 29(1): $75-81$.

10. Tatemichi tk, how acute brain failure becomes chronic: a view of the mechanisms of dementia related to stroke. neurology.1990;40:1652-1659.

11. Folstein MF, Folstein SE, McHugh PR. "Minimental state". A practical method for grading the cognitivestate of patients for the clinician. J Psychiatr Res. 1975 Nov;12(3):189-98.

12. Tangalos EG, Smith GE, Ivnik RJ, et al. The mini mental state examination in general medical practice: The utility and acceptance. Mayo clinproc 199671: 829.

13. khedr Em, Hamed SA, El-Shereef HK, et al, cognitive impairment after cerebrovascular stroke: relationship to vascular risk factors. Neuro psychiatry Dis Treat 2009;5:103-16

14. Serrano S, Domingo J, Rodriguez-Garcia E,et al. Frequency of cognitive impairment without dementia in patients with stroke: a two-year follow-up study. Stroke 2007; 38 (1):105-10.

15. Del Ser T, Barba R, Morin MM, Domingo J, Cemillan C, Pondal M, Vivancos J. Evolution of cognitive impairment after stroke and risk factors for delayed progression. Stroke. 2005 Dec; 36(12):2670-5. Epub 2005 Oct 27.
16. Rasquiun SM Lodder J, Ponds RW et al. Cognitive functioning after stroke: a one-year follow-up study. Dementia Geriatric Cognitive Disorder. 2004;18 (2): 138-44.

17. Sachdev PS, Brodaty H, Valenzuela MJ, Lorentz L, Looi JC, Berman K, Ross A, Wen W, Zagami AS. Clinical determinants of dementia and mild cognitive impairment following ischaemic stroke: the Sydney Stroke Study. Dement Geriatr Cogn Disord. 2006; 21 (5-6): 275-83. Epub 2006 Feb 10.

18. Pohjasvaara T, Erkinjuntti T, Ylikoski R, Hietanen M, Vataja R, Kaste M. Clinical determinants of poststroke dementia. Stroke. 1998 Jan; 29(1):75-81.

19. Barba R, Martínez-Espinosa S, Rodríguez-García E, Pondal M, Vivancos J, Del Ser T. Poststroke dementia : clinical features and risk factors. Stroke. 2000 Jul; 31 (7):1494-501.

20. Madureira S, Guerreiro M, Ferro JM. Dementia and cognitive impairment three months after stroke. Eur J Neurol 2001;8:621-7.

21. Rasquin SM, Lodder J, Ponds RW, et al. Cognitive functioning after stroke: a one-year follow-up study. DementiaGeriatricCognitiveDisorder2004;18(2):138-44

22. Kernan WN, Inzucchi SE, Viscoli CM, Brass LM, Bravata DM, Horwitz RI. Insulin resistance and risk for stroke. Neurology. 2002 Sep 24;59(6):809-15.

23. Sudo FK, Alves CE, Alves GS, Ericeira-Valente L, Tiel C, Moreira DM, Laks J, Engelhardt E. White matter hyper intensities, executive function and global cognitive performance in vascularmild cognitive impairment. Arq Neuropsiquiatr. 2013 Jul; 71(7):431-6. doi: 10. 1590/0004-282X20130057.

24. Gemmell E, bosomworth H, Allan L, et al. hippocampal neuronal atrophy and cognitive function in delayed post stroke and age related dementias. stroke 2012; 43:808.

\section{How to cite this article?}

Sejwar A, Gopal Krishna, A. Dhiran, Dubey T. N. Study of clinical risk factors and predictors of post stroke vascular cognitive impairment. Int J Med Res Rev 2018;6 (03):133-140. doi:10.17511/ijmrr. 2018.i03.01. 